\title{
CINÉTICA E CARACTERIZAÇÃo FÍSICO-QUíMICA DO FERMENTADO DO PSEUDOFRUTO DO CAJU (Anacardium occidentale $\mathbf{L}$.
}

\author{
Alberto B. Torres Neto, Moacir Epifânio da Silva, Wagner Barros Silva, Ramdayal Swarnakar e Flávio Luiz Honorato \\ da Silva* \\ Departamento de Engenharia Química, Centro de Ciências e Tecnologia, Universidade Federal de Campina Grande, \\ Av. Aprígio Veloso, 882, 58109-970 Campina Grande - PB, Brasil
}

Recebido em 16/3/05; aeito em 24/8/05; publicado na web em 8/2/06

\begin{abstract}
KINETIC AND PHYSICO-CHEMICAL CHARACTERIZATION OF CASHEW (Anacardium occidentale L.) WINE. The production of cashew apple wine has the purpose of minimizing the wastage in the Brazilian cashew production. Knowing that the cashew apple fermentation produces a good cashew wine, a study of alcoholic fermentation kinetics of the cashew apple and the physicochemical characterization of the product were made. The cashew wine was produced in an stirred batch reactor. The results of the physico-chemical analysis of volatiles, residual sugars, total acidity and $\mathrm{pH}$ of cashew wine showed that their concentrations were within the standard limits established by the Brazilian legislation for fruit wines.
\end{abstract}

Keywords: cashew apple wine; fermentation; physico-chemical characterization.

\section{INTRODUÇÃO}

A utilização do pedúnculo de caju para produção de fermentado (vinho), vinagre e destilado do fermentado (aguardente), entre outros, é uma forma de aproveitar a parte suculenta do fruto evitando seu desperdício exagerado, que é em torno de $85 \%$ de uma produção anual de mais de 1 milhão de t, e fazendo com que a cultura do caju seja mais valorizada, gerando emprego e renda para minimização das desigualdades regionais do Brasil, pois a região Nordeste é responsável por aproximadamente $99 \%$ da produção brasileira da fruta. $\mathrm{O}$ desperdício deve-se ao fato da industrialização da castanha, para produção de óleos e castanha comestível, ser o principal interesse comercial em relação ao fruto integral, com um alto índice de exportação desses produtos ${ }^{1}$.

Como o fermentado da fruta (vinho da fruta) de caju é produzido em pequena escala e ainda pouco comercializado, é necessário fazer as análises do mesmo, entre elas, a físico-química, para verificar a qualidade desse produto. A utilização do pedúnculo de caju para obtenção de novos produtos, como é o caso do fermentado alcoólico (vinho), requer uma adaptação dos processos de produção de vinhos pois, em nível industrial, as operações aplicadas aos processos de fermentados de frutas são adaptações da produção de vinho de uva. A preparação do fermentado de caju, como o fermentado de laranja, não é uma bebida que apresenta grande comercialização no Brasil, apesar do conhecimento acerca de sua produção ${ }^{2}$.

A análise dos componentes voláteis (acetaldeido, acetona, ésteracetato de metila e etila), metanol, etanol, álcoois superiores (1propanol, isobutanol, amílico e isoamílico), acidez total, açúcares residuais e pH são de vital importância para verificar se as características do produto estão dentro dos limites estabelecidos pela legislação brasileira ${ }^{3}$.

O acetaldeido (etanal) é formado no decorrer da fermentação alcoólica, sendo um produto do metabolismo primário da fermentação, produzido a partir de aminoácidos presentes no meio fermentativo e pela oxidação do etanol. Garruti ${ }^{3}$ afirma que um

*e-mail: flavioluizh@yahoo.com.br alto teor de acetaldeido é responsável pelo odor de oxidado do vinho de mesa. Segundo Salton et al. $^{4}$ altas concentrações de etanal no vinho ou no destilado são resultados de uma sulfitação do meio (mosto) antes da vinificação.

A acetona é encontrada normalmente no vinho nas concentrações entre 3 a $32 \mathrm{mg} / \mathrm{L}^{5}$.

Dos componentes ésteres nos vinhos e seus destilados, o acetato de etila, em geral, é o que apresenta maior quantidade ${ }^{4,5}$. Em concentrações elevadas diminuem a qualidade do vinho e do destilado, mas em teores entre 50 a $80 \mathrm{mg} / \mathrm{L}$ favorecem o aroma do vinho. Outros pesquisadores afirmam que concentrações de acetato de etila nos vinhos abaixo de $200 \mathrm{mg} / \mathrm{L}$ conferem um odor agradável, mas em concentrações maiores conferem características de vinhos com sabores deteriorados ${ }^{6}$.

A legislação brasileira ${ }^{4}$ sobre bebidas estabelece que a concentração máxima de metanol permitida nos vinhos de mesa é de 0,5 g/100 mL de álcool anidro, pois o metanol é tóxico aos seres humanos, provocando quando consumido vinho com concentrações acima do permitido, a queda do $\mathrm{pH}$ no sangue do consumidor afetando o sistema respiratório, levando à cegueira e/ou até a morte ${ }^{7}$.

O etanol é o principal componente do fermentado de fruta, sendo apenas menor que a água. A legislação brasileira estabelece que o fermentado de fruta é a bebida com graduação alcoólica de 4 a $14 \%$ em volume, a $20^{\circ} \mathrm{C}$, obtida da fermentação alcoólica do mosto de fruta sã, fresca e madura ${ }^{8}$.

Os álcoois superiores são formados no decorrer do processo fermentativo a partir de aminoácidos constituintes do meio em fermentação. Concentrações abaixo de $400 \mathrm{mg} / \mathrm{L}$ contribuem positivamente para o aroma do vinho, mas em concentrações acima desse valor, contribuem negativamente na qualidade do vinho, em função de produzirem odores desagradáveis ${ }^{3}$. Nos destilados de vinho, a legislação brasileira estabelece o limite máximo de álcoois superiores de 0,450 g/100 mL de álcool anidro ${ }^{4}$.

A acidez total, expressa em ácido acético, é a acidez titulável que determina a quantidade das funções ácidas livres presentes no suco ou no vinho. Acidez total é a soma da acidez volátil e acidez fixa. É determinada por volumetria, utilizando-se um álcali na presença de um indicador. A legislação brasileira exige que, para os 
fermentados de frutas, os teores de acidez total estejam compreendidos na faixa de 3,3 a 7,8 g/L (55 a $130 \mathrm{meq} / \mathrm{L})$. A concentração de ácido acético nos vinhos e fermentados de frutas, geralmente, representa de 60 a $95 \%$ da acidez total. O ácido acético é o principal ácido orgânico excretado no meio em fermentação, sendo expresso em acidez volátil ${ }^{9}$.

Os vinhos ou fermentados de frutas são divididos em três classes no que se refere à quantidade de açúcares residuais. A primeira classe apresenta os vinhos do tipo seco, com até $5 \mathrm{~g} / \mathrm{L}$, a segunda entre 5 e $20 \mathrm{~g} / \mathrm{L}$ são os do tipo meio seco e a terceira é a classe dos vinhos suaves, com mais de $20 \mathrm{~g} / \mathrm{L}^{9}$.

Geralmente, o fermentado de fruta apresenta $\mathrm{pH}$ variando entre 3,0 e 4,0. A análise de $\mathrm{pH}$ facilita na avaliação da resistência do produto à infecção bacteriana ou tendência a casse férrica. $\mathrm{O} \mathrm{pH}$ igual a 3,4 é o ideal para que o produto aumente a resistência às infecções ${ }^{5}$.

Os objetivos deste trabalho foram estudar o perfil cinético da fermentação alcoólica (produção do fermentado de fruta), realizar a caracterização físico-química do fermentado para confrontar com os limites impostos pela legislação brasileira sobre bebidas ${ }^{8}$ e comparar este fermentado com outros produtos.

\section{PARTE EXPERIMENTAL}

\section{Material}

A matéria-prima utilizada foi uma amostragem de pedúnculos de caju (Anacardium occidentale L.), adquiridos e selecionados na feira livre da cidade de Campina Grande/PB.

Para a produção do fermentado do pseudofruto de caju foi realizado o seguinte procedimento:

\section{Elaboração do fermentado}

A classificação e extração dos pseudofrutos foram realizadas com a seleção dos cajus para eliminar os mais defeituosos, estragados e, principalmente, aqueles que já se apresentavam em processo de fermentação e selecionar, de preferência, os mais maduros. Em seguida, lavou-se os frutos com água clorada para eliminar as sujeiras mais grosseiras e os microrganismos, deixando-os na água durante $30 \mathrm{~min}$. Separou-se o pedúnculo da castanha e procedeu-se a lavagem dos pedúnculos com água corrente para eliminar a sujeira fina e resíduos do cloro existentes na lavagem anterior. Fez-se a trituração utilizando-se um liquidificador industrial e, em seguida, filtração, com pano de algodão previamente esterilizado para obtenção do suco integral.

Depois de todo esse processo de obtenção do suco $(3,5 \mathrm{~L})$, a etapa seguinte foi prepará-lo para fermentação, verificando antes teor de sólidos solúveis, $\mathrm{pH}$ e acidez total. Com a finalidade de clarificação (visando principalmente a retirada da polpa) do mosto foi utilizada uma solução de gelatina comercial, incolor e sem sabor, a $10 \%(\mathrm{~m} / \mathrm{v})$. A correção do mosto foi feita com adição de sulfato de amônio e fosfato de potássio para suplementar as necessidades de nitrogênio e fósforo da fermentação, respectivamente. A sulfitação foi realizada com adição de metabissulfito de sódio a $10 \%(\mathrm{~m} / \mathrm{v})$ e, por último, realizou-se a primeira captalização com sacarose (açúcar comercial da marca Estrela).

A captalização (adição de sacarose), com uma concentração total de $200 \mathrm{~g} / \mathrm{L}$, foi dividida em duas partes, $30 \mathrm{~g} / \mathrm{L}$ inicialmente e $170 \mathrm{~g} / \mathrm{L}$ posteriormente, para minimizar a inibição pelo substrato (sacarose).

Terminada a preparação do mosto iniciou-se a primeira etapa da fermentação, utilizando um reator de $10 \mathrm{~L}$ (processo operado em reator de batelada agitado). Colocou-se 20 g/L do inóculo (mes- mo fermento utilizado na fabricação de pães, da marca Fleischmann, com o teor de umidade de $70 \%$ ) ao mosto e, em um intervalo de tempo de $2 \mathrm{~h}$ (estudo cinético), mediu-se o Brix, a temperatura, a concentração de álcool e a massa de levedura (biomassa), até que o Brix chegasse próximo de zero. Em seguida, adicionou-se mais sacarose (segunda captalização) iniciando a segunda etapa da fermentação, medindo novamente o Brix, a temperatura, a concentração de álcool e a massa de levedura no mesmo intervalo de tempo até o Brix se aproximar de 3,0 (equivalente a aproximadamente $35 \mathrm{~g} / \mathrm{L}$ de açúcar), visando a obtenção de um fermentado (vinho) do tipo suave.

Com o término da segunda etapa da fermentação o fermentado já estava pronto, sendo necessária apenas uma filtração com uso de uma bomba a vácuo, um funil de porcelana e papel de filtro para eliminar os resíduos da fermentação que havia no produto final (principalmente células de leveduras). Depois da filtração, engarrafou-se o fermentado em garrafas de vidro de $1 \mathrm{~L}$ fechadas com rolhas e logo depois pasteurizou-se $\left(65^{\circ} \mathrm{C}\right.$ por $\left.30 \mathrm{~min}\right)$ em banho maria, com controle de temperatura e tempo.

\section{Estudo cinético}

No processo da fermentação alcoólica da produção do fermentado de caju foram obtidos dados referentes às concentrações de substrato (sacarose), produto (etanol), biomassa (microrganismo), em intervalos de $2 \mathrm{~h}$, controle feito durante $48 \mathrm{~h}$ de processo, em um reator descontínuo na temperatura ambiente $\left(30 \pm 2{ }^{\circ} \mathrm{C}\right)$. Após $48 \mathrm{~h}$, o controle foi feito apenas $16 \mathrm{~h}$ depois $(64 \mathrm{~h})$. A fermentação foi encerrada em $64 \mathrm{~h}$, quando o grau Brix estava próximo de 3 (aproximadamente $32 \mathrm{~g} / \mathrm{L}$ de açúcar residual), para se obter um fermentado de fruta do tipo suave.

\section{Determinações físico-químicas}

A determinação da acidez total foi realizada pelo método de titulação volumétrica, usando uma solução de hidróxido de sódio 0,127 M e, como indicador, a solução alcoólica de fenolftaleina a $1 \%$.

O procedimento para análise de sacarose residual (g/L) foi realizado utilizando-se o refratômetro digital automático Acetec RDA 8600 , que media o grau Brix, na temperatura de $20^{\circ} \mathrm{C}$. No cálculo da concentração de sacarose (g/L), foi utilizada a Equação 1, que apresenta a correlação entre o grau Brix e a concentração de sacarose.

Concentração de sacarose $(\mathrm{g} / \mathrm{L})=$ grau Brix x 10,13 + 1,445

$\mathrm{O} \mathrm{pH}$ foi determinado através de um pHmetro digital ANALION PM 608.

A determinação da concentração de microrganismos ( $\mathrm{g}$ célula seca/L) foi realizada por gravimetria. Utilizou-se papel de filtro de $0,45 \mu \mathrm{m}$, previamente seco em estufa à $60^{\circ} \mathrm{C}$ por $24 \mathrm{~h}$. Retirava-se $20 \mathrm{~mL}$ da amostra do mosto em fermentação e procedia-se à filtração. O papel de filtro com os sólidos retidos era novamente colocado na estufa, nas mesmas condições da secagem apenas do papel de filtro. Para cálculo da concentração de leveduras foi feita a diferença entre os dois pesos dividido pelo volume da amostra.

A determinação da concentração de etanol (\% de etanol em volume, à $20^{\circ} \mathrm{C}$ ) no fermentado foi realizada utilizando-se o equipamento ebuliômetro. $\mathrm{O}$ ebuliômetro é composto de uma caldeira, onde fica a amostra a ser analisada, um condensador, que é acoplado à caldeira, onde são condensados vapores provenientes do líquido contido na caldeira, e uma lamparina, que fornece aquecimento à caldeira do ebuliômetro. Foram transferidos $50 \mathrm{~mL}$ da amostra para a caldeira do ebuliômetro e, logo após, encheu-se o condensador 
com água fria e acendeu-se a lamparina. Com um termômetro acoplado à caldeira, mediu-se a temperatura de ebulição da amostra, aguardando-se que a temperatura se estabilizasse, um tempo de aproximadamente $5 \mathrm{~min}$.

Utilizou-se cromatógrafo gasoso da marca Varian CP-3380 para análises de componentes voláteis e álcoois superiores. Foi utilizado um padrão, adquirido no ITEP (Instituto Tecnológico de Pernambuco), com as seguintes concentrações: aldeído (etanal): $3,15 \mathrm{mg} /$ $100 \mathrm{~mL}$; acetona: 3,02 mg/100 mL; acetato de etila: 4,96 mg/100 $\mathrm{mL}$; metanol: 2,73 mg/100 mL; n-propanol: $6,03 \mathrm{mg} / 100 \mathrm{~mL}$; isobutanol: 4,42 mg/100 mL; n-butanol: 3,10 mg/100 mL; iso-amílico: $3,20 \mathrm{mg} / 100 \mathrm{~mL}$. O cromatógrafo estava equipado com uma coluna empacotada, nas seguintes condições operacionais: temperatura de 130,160 e $86^{\circ} \mathrm{C}$ para injetor, detector e coluna, respectivamente. Utilizou nitrogênio como gás de arraste, com velocidade de $20 \mathrm{~mL} / 40 \mathrm{~s}$.

\section{RESULTADOS E DISCUSSÃO}

\section{Cinética da fermentação alcoólica do vinho de caju}

A Figura 1 apresenta os perfis de decaimento de substrato (S), crescimento (produção) de biomassa (X) e produção de etanol (P), ambos em $\mathrm{g} / \mathrm{L}$, em função do tempo de fermentação. Analisando os resultados obtidos, verifica-se que durante o processo de fermentação houve decaimento da concentração de sacarose (S) até $14 \mathrm{~h}$ de fermentação, em decorrência do consumo do substrato pelo microrganismo, até atingir níveis próximos de $10 \mathrm{~g} / \mathrm{L}$. Depois de $15 \mathrm{~h}$ de fermentação, adicionou-se a segunda parcela de sacarose (chaptalização) o que ocasionou aumento na concentração da sacarose, divisão da chaptalização em duas etapas, prática executada para minimizar a inibição pelo substrato ${ }^{10}$. Com o passar do tempo, a concentração de sacarose (S) começou novamente a decrescer, pela ação dos microrganismos, verificando-se um decaimento mais lento em relação à primeira etapa da fermentação (início do processo), devido à presença de maiores concentrações de etanol. Observou-se que, após $10 \mathrm{~h}$ de fermentação, ocorreu uma diminuição na velocidade de produção, o que pode ser explicado pelo reflexo da inibição pelo produto. Entretanto, ao final de $48 \mathrm{~h}$, obteve-se uma concentração de etanol próxima de $100 \mathrm{~g} / \mathrm{L}$, resultando em um fermentado com aproximadamente $10 \%$ de etanol em volume, à $20^{\circ} \mathrm{C}$. Analisando a concentração de células $(\mathrm{X})$, percebe-se que durante as primeiras $5 \mathrm{~h}$ de fermentação houve pequeno crescimento celular, o que não se verificou após $10 \mathrm{~h}$ de fermentação, onde pôde-se visualizar uma estabilização do crescimento. Observou-se, portanto, que após 35 h, começa um pequeno decaimento da curva de concentração de biomassa.

A utilização de leveduras (Saccharomyces cerevisiae), em uma concentração de $20 \mathrm{~g} / \mathrm{L}$, mostrou-se adequada para obtenção de teores alcoólicos dentro dos padrões exigidos para uma fermenta-

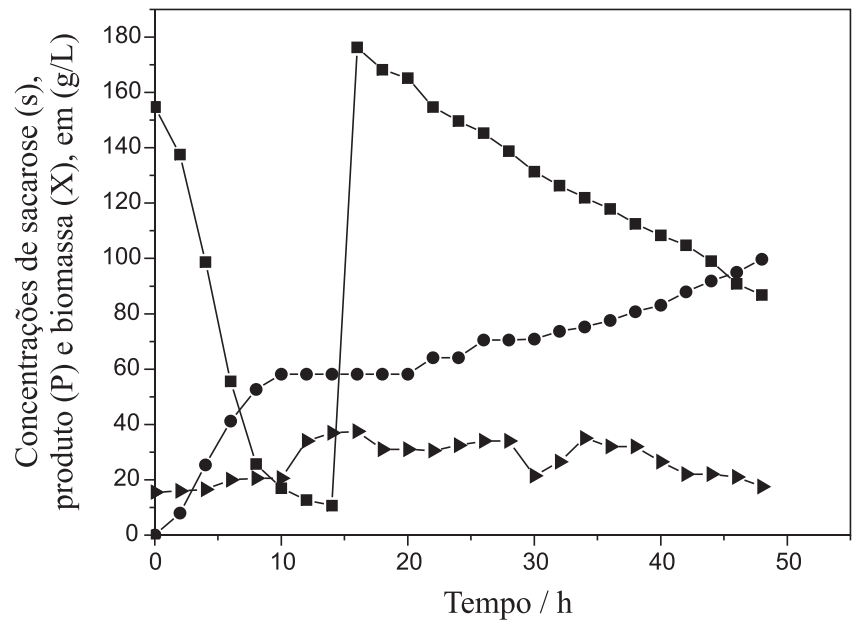

Figura 1. Cinética fermentativa da produção de fermentado de caju: concentração de açúcar $(\square S)$, concentração de etanol $(\bullet P)$ e concentração de levedura $(\backslash X)$ (expressas em $\mathrm{g} / \mathrm{L})$

ção alcoólica. Silva ${ }^{10}$ verificou que as concentrações ideais de leveduras, objetivando a produção de etanol e minimizando sua utilização para o crescimento celular, estão situadas em torno de $20 \mathrm{~g}$ de levedura para cada $\mathrm{L}$ de mosto.

\section{Caracterização físico-química do fermentado de caju}

A Tabela 1 apresenta os resultados das análises físico-químicas do fermentado produzido do pseudofruto de caju.

Já é consenso que os fermentados de frutas devem ser do tipo suave, sendo apenas bem apreciado o vinho seco de uva. $O$ fermentado de caju avaliado neste trabalho é do tipo suave, por possuir teores de açúcares residuais acima de $20 \mathrm{~g} / \mathrm{L}$, o que determina a legislação brasileira ${ }^{8}$.

Quanto ao teor de álcool etílico (11,5\%), expresso em \% de etanol em volume à $20^{\circ} \mathrm{C}$, verifica-se que o fermentado produzido está dentro do que estabelece a legislação brasileira sobre bebidas, ou seja, do Artigo 72 da Seção 2 do Decreto $n^{\circ} 2.314$, de 4 de setembro de $1997^{\circ}$.

A acidez total do vinho deve estar na faixa de 3,3 a 7,8 g/L 9 . Observando-se a Tabela 1 , verifica-se que o fermentado do pseudofruto de caju apresenta concentração de 7,2 g/L.

$\mathrm{O}$ pH de 3,5 confere ao fermentado de caju maior resistência às infecções (contaminações por microrganismos) $)^{5}$. Verifica-se que o pH abaixou de 3,7 no mosto para 3,5 no fermentado, sendo o aumento de acidez total no fermentado em relação ao início da fermentação de duas vezes, o que mostra que não houve excesso de produção de ácido. A produção alta de acidez total confere um gosto desagradável de vinagre ao produto.

Tabela 1. Comparação do fermentado (vinho) de caju com outros fermentados da literatura

\begin{tabular}{lccccc}
\hline Fermentado & $\mathrm{pH}$ & Acidez total $(\mathrm{g} / \mathrm{L})$ & Grau Brix & Álcool(\%v/v) & Odor assimilado \\
\hline Caju deste trabalho & 3,5 & 7,2 & 3,6 & 11,5 & de caju \\
Laranja $^{2}$ & 3,3 & 8,1 & 8,0 & 10,6 & de laranja \\
Caju $^{3}$ & 3,6 & 6,0 & $3,5^{*}$ & 8,5 & de caju \\
Caju $^{11}$ & 3,2 & 3,3 & 4,0 & 11,8 & de caju \\
Cajá $^{12}$ & 3,5 & 2,0 & 2,0 & 12,0 & de cajá \\
Uva $^{13}$ (vinho branco) & 3,3 & 4,1 & $3,0^{*}$ & 12,2 & de uva \\
Uva $^{13}$ (vinho tinto) & 3,6 & 4,4 & 12,0 & de uva \\
\hline
\end{tabular}

* Valores de açúcares redutores $(\mathrm{g} / \mathrm{L})$ 
Tabela 2. Análises dos componentes voláteis, metanol e álcoois superiores do vinho de caju (concentração expressa em mg/L de álcool anidro)

\begin{tabular}{lcccccccc}
\hline Etanal & Acetona & Acet. de etila & Metanol & N-propanol & Isobutanol & N- butanol & Isoamílico \\
\hline 690 & 5,3 & 46,0 & 100 & 147 & 410 & 7,0 & 1550 \\
\hline
\end{tabular}

Comparando-se os fermentados de frutas de caju, laranja, cajá e os vinhos branco e tinto, verifica-se que (Tabela 1) o $\mathrm{pH}$ e a concentração de etanol nos fermentados são relativamente próximos, estando apenas o fermentado de caju ${ }^{3}$, que é a média de 6 amostras em diferentes tratamentos de temperatura $\left(18\right.$ e $\left.30^{\circ} \mathrm{C}\right)$ e teor de $\mathrm{SO}_{2}$ livre $(0,50,100$ e $200 \mathrm{ppm})$, com concentração de etanol abaixo de $10 \%$. Quanto ao grau Brix remanescente, os fermentados de caju estão bem próximos, em torno de 4,0, enquanto o fermentado de laranja apresenta uma concentração final de 8,0 e o de cajá de 0,0 (fermentado de cajá do tipo seco). Os valores dos fermentados de caju ${ }^{3}$, vinho branco e vinho tinto ${ }^{13}$ estão expressos em açúcares redutores (g/L), apresentando concentrações inferiores a 5,5 g/L, valor máximo estabelecido pela legislação brasileira para vinhos secos. A acidez total do fermentado de caju ${ }^{11}(3,3 \mathrm{~g} / \mathrm{L})$ está bem abaixo das concentrações dos fermentados de laranja ${ }^{2}$ $(8,1 \mathrm{~g} / \mathrm{L})$ e de caju deste trabalho $(7,2 \mathrm{~g} / \mathrm{L})$. As baixas concentrações de acidez total nos vinhos branco e tinto, dão características de vinhos macios, com mais estrutura e aromas mais complexos ${ }^{13}$. Comparando-se o fermentado de caju deste trabalho com os vinhos branco e tinto, observam-se valores físico-químicos analisados semelhantes.

A Tabela 2 apresenta os valores das análises dos componentes voláteis, metanol e dos álcoois superiores das amostras do fermentado de caju. Nota-se que o fermentado de caju produzido apresenta estes constituintes abaixo do máximo especificado pela legislação brasileira.

O acetaldeído representa cerca de $90 \%$ da concentração total dos aldeídos de vinho e destilado do vinho e é um produto da oxidação do etanol ${ }^{4}$. Vinhos brancos ou produtos semelhantes, como é o caso do fermentado produzido neste trabalho, que apresentam concentração acima de $700 \mathrm{mg} / \mathrm{L}$ de álcool anidro indicam que o produto ou foi submetido à aeração (arejado ou oxidado) ou a doses elevadas de sulfitação do mosto antes da fermentação alcoóli$\mathrm{ca}^{4,5}$. Pode-se observar que o fermentado de caju tem uma concentração ligeiramente inferior a $700 \mathrm{mg} / \mathrm{L}$ de acetaldeído (etanal).

A concentração de acetona no fermentado de caju foi de $5,3 \mathrm{mg} / \mathrm{L}$ de álcool etílico anidro. Em vinhos de uva, as concentrações de acetona estão na faixa de 3 a $32 \mathrm{mg} / \mathrm{L}$ de álcool anidro ${ }^{5}$.

$\mathrm{O}$ acetato de etila apresentou concentração de $46 \mathrm{mg} / \mathrm{L}$ de álcool anidro. Concentrações entre 50 a $80 \mathrm{mg} / \mathrm{L}$ contribuem para o aroma do produto ${ }^{3}$.

Entre os constituintes analisados, enfatiza-se o metanol como um dos mais importantes, pois sua produção é indesejável e caso ocorra, não deve ultrapassar o limite de $35 \mathrm{mg} / 100 \mathrm{~mL}$ da bebida ou $500 \mathrm{mg}$ de metanol/100 mL de álcool anidro ${ }^{4,5}$. Como se pode observar na Tabela 2, o valor do metanol foi inferior ao máximo permitido, não chegando a $3 \%$ do valor máximo, o que demonstra que a retirada da pectina do mosto foi bastante eficiente, pois no processo de fermentação alcoólica o metanol é formado pela degradação da pectina, um polissacarídeo presente no suco do caju ${ }^{7}$.

A concentração máxima estabelecida pela legislação brasileira de álcoois superiores é de $4500 \mathrm{mg} / \mathrm{L}$ de álcool anidro ${ }^{4}$. Verificase, pela Tabela 2, que o máximo foi de $2114 \mathrm{mg} / \mathrm{L}$. Assim, o produto não ultrapassou o limite máximo permitido para a soma dos álcoois superiores no fermentado.

A produção de fermentado do pseudofruto do caju para pequenos e médios produtores de cultura do cajueiro poderá acrescentar maiores ganhos econômicos. As análises físico-químicas mostraram que o fermentado de caju do tipo suave apresenta qualidades comparáveis a outros fermentados de frutas, como o de laranja, de cajá, de caju e dos vinhos de uva produzidos por outros pesquisadores.

\section{REFERÊNCIAS}

1. Holanda, J. S.; Oliveira, A. J.; Ferreira, A. C.; Pesq. Agropec. Bras. 1998, 33, 787.

2. Corazza, M. L.; Rodrigues, D. G.; Nozaki, J.; Quim. Nova 2001, 24, 449.

3. Garruti, D. S.; Tese de Doutorado, Universidade Estadual de Campinas, Brasil, 2001.

4. Salton, M. A.; Daudt, C. E.; Rizzon, L. A.; Ciênc. Tecnol. Aliment. 2000, 20, 302 .

5. Hashizume, T. Em Biotecnologia na Produção de Alimentos; Aquarone, E.; Borzani, W.; Schmidell, W.; Lima, U. A., eds.; Edgard Blücher Ltda: São Paulo, 2001, cap. 2.

6. Oliveira, E. S.; Tese de Doutorado, Universidade Estadual de Campinas, Brasil, 2001.

7. Cardoso, M. G.; Produção de Aguardente de Cana-de-açúcar, Ed. UFLA: Lavras, 2001.

8. Brasil, Decreto n ${ }^{0} 2314,4$ set. 1997, Diário Oficial da União, Brasilia, 05 de set., 1997.

9. Rizzon, L. A.; Zanuz, M. C.; Manfredini, S.; Como Elaborar Vinho de Qualidade na Pequena Propriedade, $3^{\mathrm{a}}$ ed., Embrapa: Bento Gonçalves, 1994.

10. Silva, F. L. H.; Tese de Doutorado, Universidade Estadual de Campinas, Brasil, 1998.

11. Costa, A. G. F.; Oliveira, C. S.; Lopes, F. L.G.; Santana, J. C. C.; Souza, R. R.; Anais do XIV Simpósio Nacional de Fermentações, Florianópolis, Brasil, 2003.

12. Dias, D. R.; Schwan, R. F.; Lima, L. C. O.; Ciênc. Tecnol. Aliment. 2003, 23,342 .

13. Embrapa uva e vinho; Comunicado Técnico. Avaliação Nacional de VinhosSafra 2000: Características Sensoriais e Físico-Químicas dos Vinhos, 2000. 